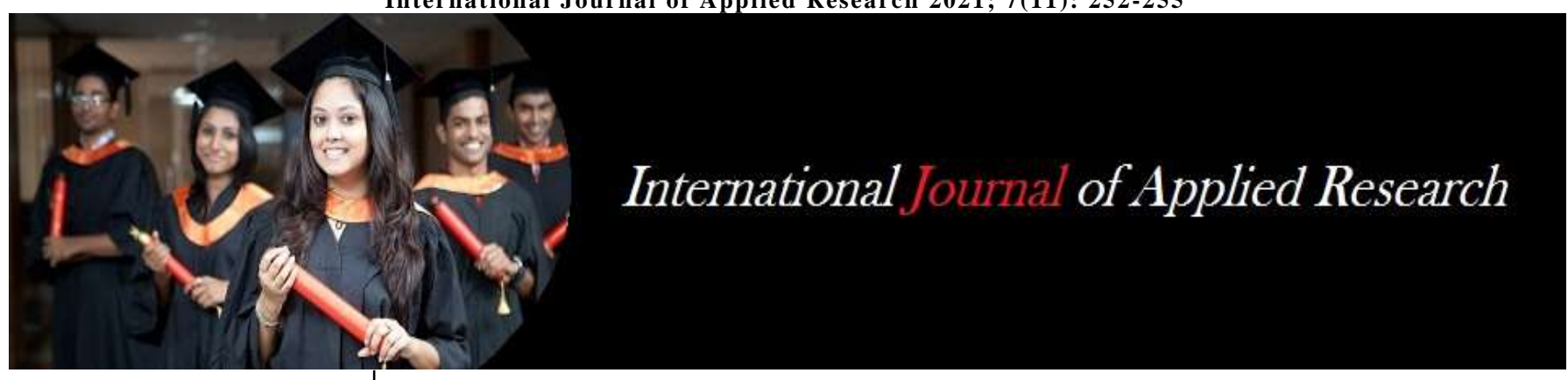

ISSN Print: 2394-7500

ISSN Online: 2394-5869

Impact Factor: 8.4

IJAR 2021; 7(11): 252-255

www.allresearchjournal.com

Received: 25-09-2021

Accepted: 27-10-2021

डॉ. अनु रस्तोगी

विभागाध्यक्ष व एसोसिएट प्रोफेसर, समाजशास्त्र विभाग, आर. जी. पी जी. कॉलेज, मेरठ, उत्तर प्रदेश, भारत

हिमानी शर्मा

पी. एच्. डी. शोधार्थी, समाजशास्त्र विभाग, आर. जी. पी. जी. कॉलेज, मेरठ, उत्तर प्रदेश, भारत

Corresponding Author: हिमानी शर्मा

पी. एच. डी. शोधार्थी, समाजशास्त्र विभाग, आर. जी. पी. जी. कॉलेज, मेरठ, उत्तर प्रदेश, भारत

\section{राष्ट्र निर्माण में महिलाओं की भूमिका का ऐतिहासिक और समकालीन समाजशास्त्रीय विश्लेषण}

\section{डॉ. अनु रस्तोगी, हिमानी शर्मा}

DOI: https://doi.org/10.22271/allresearch.2021.v7.i11d.9138

\section{सारांश}

किसी भी राष्ट्र को सुद्धढ, सशक्त व आत्मनिर्भर बनाने का लक्ष्य उस राष्ट्र के प्रत्येक नागरिक को सशक्त बनाकर ही प्राप्त किया जा सकता है, जिसके लिए महिलाओं व पुरुषों दोनों के सम्मिलित प्रयास आवश्यक हैं। यदि महिलाओं की स्थिति सुदढ़ है तो निथ्चित ही देश भी सुदढ़ व सशक्त होगा। बदलती परिस्थितियों के साथ भारत में महिलाओं को सशक्त बनाने के प्रयासों के प्रभाव परिलक्षित हो रहे हैं। वर्तमान में महिलाओं की सामाजिक आर्थिक राजनीतिक हिस्सेदारी बढ़ी है। उन्होंने पुरुष वर्चस्व वाले समाज में अपनी विशिष्ट पहचान बनाई है। बदलते परिवेश में कार्यशील महिलाओं ने दोहरे दायित्व का निभाकर अपनी दोगुनी शक्ति का प्रदर्शन कर सिद्ध किया है कि समाज की प्रगति पुरुष और महिला दोनों की साझा जिम्मेदारी है। इस शोध पत्र में राष्ट्र निर्माण की प्रक्रिया में महिलाओं की भूमिका के इतिहास, वर्तमान व भविष्य की उन्नत आकांक्षाओं को विभिन्न आधारों पर विश्लेषित करने का प्रयास किया गया है। राष्ट्र निर्माण हेतु महिलाओं के वैयक्तिक व सामूहिक प्रयासों को भी दर्शाया गया है क्योंकि महिलाओं का प्रत्येक प्रगतिशील कदम चाहें वह अपनी रूचि के क्षेत्र में हो या नवीन व्यवसाय में, महिलाओं को आत्मनिर्भर व सुदढ़ बनाने के साथ-साथ संपूर्ण राष्ट्र के विकास में सहयोगी होता है।

कूटशब्द: राष्ट्र निर्माण, महिलाओं की भूमिका, समकालीन समाजशास्त्रीय विश्लेषण

\section{प्रस्तावना}

संपूर्ण विध्ध में नारी महिमा का उद्धोष उसी समय हो गया था जब भारतीय ऋषियों ने अथर्ववेद में "माता भूमि: पुत्रो अहं पृथ्वियां" (अर्थात भूमि मेरी माता है और हम इस भूमि के पुत्र हैं) की प्रतिष्ठा की थी। नेपोलियन बोनापार्ट ने स्त्री की महत्ता को बताते हुए कहा था "आप मुझे एक योग्य माता दो, मैं तुक्हें एक योग्य राष्ट्र दूँगा"। भारतीय जनजीवन व संस्कृति का केंद्र भी सदैव स्त्री ही रही है। सशक्त महिलाएं ही सशक्त समाज की आधारशिला है। राष्ट्र के समग्र विकास व निर्माण में महिलाओं के योगदान की कोई निश्चित सीमा नहीं है। उन्होंने देश के बहुदिशीय विकास व प्रगति में स्वयं की भागीदारी को उत्कृष्ट ढंग से सुनिश्चित किया है। वर्तमान में स्वयं के अस्तित्व की स्वतंत्रता को बनाए रखने हेतु महिलाएं अनेक क्षेत्रों में पुरुषों से आगे निकल चुकी हैं। विज्ञान, अंतरिक्ष, प्रौद्योगिकी, शिक्षा, चिकित्सा, राजनीति, खेल कूद, मनोरंजन, अध्यापन, इंजीनियरिंग, व्यापार, साहित्य, प्रबंधन, कानून, प्रशासन, समाज सेवा, अनुसंधान, मीडिया, पर्यटन तथा अन्य अतिदक्षता वाले क्षेत्रों में भी महिलाओं की उपलब्धि ने स्वयं उनको आत्मनिर्भर बनाने के साथ-साथ राष्ट्र निर्माण में भी योगदान दिया।

अध्ययन का उद्देश्य

इस अध्ययन का मूल उद्देश्य भारत की विकास यात्रा में महिलाओं के योगदान को स्पष्ट करना है। अनुसंधान के मुख्य उद्देश्य निम्नोक्त है। 
1. राष्ट्र निर्माण के मार्ग में महिलाओं के योगदान का वर्णन करना।

2. समकालीन भारत में महिला श्रम सहभागिता की प्रासंगिकता का विश्लेषण करना।

3. परिवर्तित वैध्धिक परिदृश्य में महिला कार्य बल में वृद्धि की उपयोगिता व आवश्यकता की जांच करना।

अध्ययन की सीमा

इस अध्ययन का विस्तार राष्ट्र निर्माण के मार्ग में महिलाओं के योगदान का ऐतिहासिक व समकालीन पृष्ठभूमि में विश्लेषण करने तक सीमित रहेगा।

\section{अनुसंधान कार्यविधि}

यह अध्ययन वर्णनात्मक, व्याख्यात्मक, आलोचनात्मक, विश्लेषणात्मक व मूल्यांकनात्मक विधियों का प्रयोग कर राष्ट्र निर्माण में शहरी, ग्रामीण व पर्वतीय क्षेत्रों की महिलाओं की विविधि क्षेत्रों में अनेकों भूमिकाओं के महत्व व योगदान के बिंदुवार वर्णन पर केंद्रित रहेगा।

तथ्यों का संकलन

शोध अध्ययन के लिए द्वितीयक स्रोतों से आंकड़ों को एकत्रित कर विश्लेषण किया गया है। द्वितीयक स्रोत वे हैं, जो राष्ट्रीय निर्माण व इस संदर्भ में महिलाओं के योगदान की जानकारी प्रदान करते हैं। माध्यमिक स्रोतों में पुस्तक, शोध पत्र, शोध निबंध, शोधगंगा, ईसंसाधन, विकिपीडिया व ब्रिटानिका आदि सम्मिलित है।

समाज निर्माण में महिलाओं की ऐतिहासिक भूमिका: राष्ट्र निर्माण की प्रक्रिया में महिलाओं के योगदान का लंबा इतिहास रहा है। प्राचीन काल से ही भारत में महिलाओं को उचित स्थान प्राप्त था। महिलाएं भी पुरुषों की तरह धार्मिक, आर्थिक,राजनीतिक, सामाजिक व सांस्कृतिक दायित्वों का निर्वाह करती थीं। याजवल्क्य की धर्मपत्री गार्गी के अध्यात्मिक ज्ञान से सभी परिचित हैं। कालिदास को संस्कृत का प्रकांड पंडित बनाने के पीछे एक नारी विद्योत्त्मा थी। तुलसीदास को भक्ति मार्ग दिखाने वाली भी उनकी पत्नी रत्नावली थी। सीता, सावित्री नारी आदर्श की प्रतिमूर्ति रहीं तथा मै*्रैयी, घोषा, अपाला ने आध्यात्मिकता के आयाम स्थापित किए। रानी लक्ष्मीबाई, रजिया सुल्तान, मीरा व पद्मिनी ने क्रमश: शौर्य, साहस, भक्ति व स्वाभिमान के आदर्श स्थापित किए। हाड़ी की रानी व सारन्धा रानी बलिदान व दायित्व निर्वाह के लिए जानी जाती है। 1857 की क्रांति में रानी अवंतिका बाई लोधी, चौहान रानी, रानी चेन्नम्मा, बेगम हजरत महल आदि ने देश को स्वतंत्र कराने में अपना सर्वस्व योगदान दिया। स्वतंत्रता आंदोलन कालखंड में सुचेता कृपलानी, भगिनी निवेदिता,अरूणा आसिफ अली, एनी बेसेंट, सरोजिनी नायडू, मैडम भीकाजी कामा, कैप्टन लक्ष्मी सहगल आदि ने अपना योगदान दिया। इतिहास साक्षी है जब-जब महिला समाज में महिलाओं को अधिकार का अवसर प्रदान किए हैं तब-तब महिलाओं ने विश्ध के समक्ष श्रेष्ठ उदाहरण प्रस्तुत किए हैं।

महिला व राष्ट्र निर्माण का समकालीन स्वरूप: वर्तमान में महिला जगत का एक बहुत बड़ा भाग अपनी संवादहीनता, भीरुता व संकोचशीलता को त्याग कर स्वयं के लिए नई संभावनाओं, नए अवसरों का चयन कर नए मार्ग बना रहा है। वर्तमान में नारी शक्ति का
ये प्रसार इतना घनीभूत हो चुका है कि कोई भी क्षेत्र इनके संपर्क से अछूता नहीं है। भारतीय पुलिस बल में 8.98 प्रतिशत भाग महिलाओं का है। देश की विभिन्न अदालतों में कुल न्यायाधीशों की संख्या का 27.6 प्रतिशत तथा विशेषतः हाईकोर्ट के न्यायाधीशों में 10 प्रतिशत महिलाओं द्वारा निर्मित है। "ह्यूमन रिसोर्स फॉर हेल्थ इन इंडिया" के अनुसार भारत में 17 प्रतिशत डॉक्टर्स महिलाएं हैं, जिनमें से 6 प्रतिशत ग्रामीण क्षेत्रों से आती हैं।

विविध दायित्वों का निर्वाहः महिलाएं प्रत्यक्ष व अप्रत्यक्ष रूप से राष्ट्र निर्माण में सहयोग देती है। वे माता के रूप में अपनी भूमिका निभाते हुए अपने संतानों में संस्कार, गुण, कर्तव्य व उत्तरदायित्व का पोषण करती हैं जो राष्ट्र निर्माण के निर्धारक तत्व है। यह कहावत सर्वविदित है कि हर सफल मनुष्य के पीछे किसी न किसी महिला का हाथ होता है। संस्कृति, मूल्य व परंपराओं की संरक्षिका के रूप में महिलाएं माता,पत्नी,बहन व बेटी के दायित्वों को निभा कर देश की सांस्कृतिक पूंजी का संचार नई पीढ़ी में करती हैं।

वृहत स्तर पर महिला कार्यबल: महिलायें स्वयं को आत्मनिर्भर बनाने, स्वयं के अधिकारों के प्रति लड़ने व अन्याय के विरुद्ध आवाज उठाने लगी हैं। वृहद स्तर पर महिला आयोग, महिला व बाल कल्याण मंत्रालय, महिला मुक्ति मोर्चा जैसी व्यापक संस्थाएं हैं, जो न केवल महिला हितों की रक्षा करती हैं वरन् अपराधियों को उचित दंड दिलवाकर अनुकूल वातावरण का निर्माण भी करती हैं। लघु स्तर पर महिला कार्य बल स्वयं सहायता समूह जैसी लोकतांत्रिक संस्थाएं महिलाओं में कौशल का विकास कर उन्हें धन उपार्जन योग्य बनाती हुए उनमें आत्मविधास जगाती हैं। आंध्र प्रदेश व केरल जैसे राज्यों में माइक्रोफाइनेंस, स्वयं सहायता समूह, SEWA, दसरा, कुडम्बश्री व प्रदान जैसे संगठनों के निर्माण ने महिलाओं की उपार्जन क्षमता को स्पष्ट किया है। भारत में महिलाओं द्वारा सूक्ष्म स्तर से प्रारंभ किए गए उद्योग जैसे लिज्जत पापड, आचार व्यवसाय, खादी वस्त्र व हस्तशिल्प अब देश-विदेश में स्वयं की पहचान बना चुके हैं।

लघु स्तर पर महिला कार्यबल: भारतीय ग्रामीण महिलाएं स्थानीय स्तर पर बांस, लकड़ी, मिट्टी के बर्तन, समान बनाकर तथा सिलाई, कढ़ाई, हथकरघा, जरी, मीना, नक्काशी द्वारा सांस्कृतिक पूंजी के निर्माण के साथ ही देश की अर्थव्यवस्था को भी लाभ पहुंचाते हैं। भारत में 28 लाख आंगनबाड़ी कार्यकर्ता, सहायिका तथा लगभग 10.50 लाख आशा कार्यकर्ताओं की महिला शक्ति है, सामुदायिक स्तर पर कार्य कर रहीं ये महिलाएं कोविड-19 संक्रमण काल में भी अपनी भूमिका निभा रही हैं। वृहद स्तर तथा लघु स्तर पर महिला कार्य क्षमता के साथ ही उन महिला समुदायों की ओर भी ध्यान दिया जाना चाहिए, जिन महिला कामगारों की किसी भी सर्वेक्षण या रिपोर्ट में गिनती ही नहीं की जाती है। 1992 में समाजशास्त्री गेल ओम्वेट ने एक स्थान में कार्यशील 239 महिला कामगारों को पाया जिनकी संख्या जनगणना रिपोर्ट में मात्र 38 ही गिनी गई थी। ऐसे ही दूसरे क्षेत्र में कार्यरत महिलाओं की संख्या 444 थी, जिनमें से केवल 9 ही जनगणना सूची में सम्मिलित की गई थीं। इस प्रकार श्रम शक्ति का एक भाग अद्श्य ही रह जाता है।

शहरी क्षेत्रों में महिलाओं के लिए अवसर, साधन व सुविधाओं के अन्य स्रोत उपलब्ध होते हैं, जिनके कारण वे जिस भी क्षेत्र में रुचि रखती हैं, उसी क्षेत्र में आगे बढ़ सकती हैं। वर्ष 2017-2018 के आंकड़ों के अनुसार महिलाओं के श्रम शक्ति भागीदारी दर [LFPR] केवल 23.3 
प्रतिशत ही है, जो कि 2004-2005 में 42.7 से काफी कम हो गई है। यह विचारणीय तथ्य है कि महिलाएं स्वेच्छा से काम छोड़ रही है या कोई संरचनात्मक व्यवधान इसके लिए उत्तरदायी है। यदि ऐसा हो तब सरकार को नीति निर्माण स्तर पर हस्तक्षेप करना चाहिए। एक अनुमान के अनुसार यदि महिलाओं की कार्यबल भागीदारी के मार्ग से व्यवधानों का निस्तारण हो सके तो 2025 तक देश की जी.डी.पी. 700 बिलियन अमेरिकी डॉलर तक बढ़ सकती है।

अधिकांश ग्रामीण महिलाएं कृषि व्यवसाय से जुड़ी होती हैं। इसके अलावा स्वयं सहायता समूहों, हस्तशिल्प, बुनाई, कताई, पशुपालन व छोटे-बड़े निर्माण कार्यों से जुड़ी रहती हैं। भारतीय हस्तशिल्प जनगणना के अनुसार भारत में 56.13 प्रतिशत कारीगर महिलाएं हैं। महिला किसान के रूप में भी खाद्यान्न, पारिस्थितिकी, प्राकृतिक संसाधनों के साथ सह-अस्तित्व रखते हुए स्वयं को आर्थिक रूप से सशक्त बनाती आईं हैं। खादी उद्योग में लगे $\mathbf{4}$ लाख बुनकरों में भी महिलाओं की संख्या पुरुषों से अधिक है। इसके साथ ही यह ऊन उत्पादन, गौशाला प्रबंधन, शहद उत्पादन, रेशम उत्पादन, मशरूम की खेती जैसे कार्यों से जुड़ी रहती हैं।

पहाड़ी महिलाएं विपरीत परिस्थितियों से उबर कर कंबल, रजाई, रेशम स्टॉल, पश्मीना सिल्क आदि का उत्पादन करती है। उत्तराखंड के पिथौरागढ़ में अवनी समाज ने आजीविका हेतु कुमाऊनी महिलाओं को सशक्त बनाने के लिए उनमें उद्यमशीलता के सिद्धांतों व कौशल को विकसित करने की खेती का प्रसंस्करण किया।

विभिन्न क्षेत्रों में महिलाएं: भारतीय महिलाओं में अपने कार्यों को अत्यधिक कार्यकुशलता से तथा सामान्य से अधिक समय तक करने की क्षमता होती है इसी कारण वे जिस भी क्षेत्र में संलग्न होती है उनका नाम ही उनके क्षेत्र का परिचय दे देता है।

- आर्थिक क्षेत्र: भारतीय स्टेट बैंक के चेयरपर्सन अरुंधति

- भट्टाचार्य इस पद पर पहुंचने वाली प्रथम महिला बनीं। ICICI की $\mathrm{CEO}$ व $\mathrm{MD}$ चंदा कोचर ने पुरुष वर्चस्व वाले क्षेत्र में महिला नेतृत्व शक्ति का परिचय दिया। किरण मजूमदार, नीता अंबानी, इन्द्रा नूई, मल्लिका श्रीनिवासन, निशा गोदरेज, विनीता डी गुप्ता, रोशनी नादर व शिखा शर्मा जैसी महिलाएं किसी परिचय पर आश्रित नहीं है।

- समाज सेवा: महिलाओं का भावनात्मक पक्ष पुरुषों की अपेक्षा अधिक सहानुभूतिपरक होता है, जिस कारण वह समाज सेवा के क्षेत्र में अधिक प्रभावी होती हैं। सिंधुताई सपकाल का अनाथ बच्चों का पोषण, मेधा पाटकर का पर्यावरण संरक्षण, अरुणा रॉय की भषष्टाचार विरोधी व सरकारी पारदर्शिता लेने की लिए लड़ाई, "आयरन लेडी" इरोम शर्मिला, यौन तस्करी के पीड़ितों की मदद करने वाली रंगू सौरिया, एचआईवी एक्टिविस्ट ज्योति धवन, पद्मश्री अनिता रेड्डी का झुग्गी वासियों के पुनर्वास व उत्थान हेतु समर्पण महिलाओं की उपलब्धियों को बताते हैं।

- शैक्षिक योगदान: भारत में प्राथमिक शिक्षकों में 51.21 प्रतिशत तथा उच्चतर शिक्षा में 42.21 प्रतिशत भाग महिला शिक्षकों का है। वर्तमान में बढ़ती जागरूकता ने शिक्षा के महत्व को समझा कर महिला साक्षरता दर को 65.46 प्रतिशत तक पहुंचा दिया, जिसमें प्रत्येक दशक निरंतर वृद्धि आंकी जा सकती है। लीला दुबे, वीना मजूमदार, इरावती कर्वे, शर्मिला रेगे, किरण देसाई,
सरोजिनी नायडू, शैला ब्रजनाथ तथा अन्य महिला शिक्षाविदों ने स्वयं के विकास के साथ-साथ आने वाली पीढ़ी का विकास भी सुनिश्चित किया।

- वैज्ञानिक योगदान: महिलाएं देश की प्रगति को सुनिध्चित करने हेतु वैज्ञानिक क्षेत्र में अपना परचम लहरा रही है । एंटीकैंसर ड्रग डिस्कवरी करने वाली सीमा भटनागर, अग्नि-5 मिसाइल की योजना का प्रतिनिधित्व करने वाली टेसी थॉमस, गगनदीप कांग, मंगला मणि, चंद्रमा शाह, कामाक्षी शिवरामकृष्णन, मुथैया वनीता, रितु करिघल आदि वैज्ञानिक के रूप में महिला शक्ति का परिचय दे रही है।

- राजनीतिक क्षेत्र: लोकतंत्र में महिलाओं की राजनीतिक भागीदारी देश को अभूतपूर्व लाभ दे सकती है। स्वर्गीय सुषमा स्वराज, स्मृति ईरानी, मेनका गांधी, सोनिया गांधी, ममता बनर्जी, जयललिता, इंदिरा गांधी, वसुंधरा राजे, शीला दीक्षित तथा अन्य अनेक महिलाओं ने लोकसभा, राज्यसभा, विधानसभा, स्थानीय निकाय, नगर पालिका व ग्राम पंचायत के स्तर पर अपना योगदान देकर एक मजबूत एवं जीवंत लोकतंत्र निर्माण करने का सफल प्रयास किया।

- प्रशासनिक क्षेत्र: भारत में महिला आईएएस अधिकारियों की संख्या तुलनात्मक रूप से कम होते हुए भी महिला प्रशासनिक अधिकारी अपनी समर्पण व प्रतिबद्धता को सिद्ध करते हुए पूरे देश को प्रेरित कर रही हैं। अरुणा सुंदरराजन, दुर्गा शक्ति नागपाल, पूनम मालकोंडया, इरा सिंघल, बी चंद्रकला, स्मिता सबरवाल तथा विजय जाधव देश की सर्वश्रेष्ठ आईपीएस अधिकारियों में गिनी जाती है।

- पुलिस प्रशासन: देश की पहली महिला आईपीएस अधिकारी किरण बेदी द्वारा प्रारंभ इस सफर में अनेकों महिलाओं का साथ जुड़ गया है। अर्चना रामासुंदरम, मीरा बोरवंकर, कंचन चौधरी भट्टाचार्य, सोनिया नारंग, संजुक्ता पराशर आदि इसी क्षेत्र में मिसाल बन गई हैं। विमला मेहरा देश की पहली महिला स्पेशल कमिक्षर पुलिस है जो किरण बेदी के बाद दिल्ली की तिहाड जेल की दूसरी महिला महानिदेशक बनीं।

- खेल क्षेत्र: भारतीय महिलाएं खेल जगत में दिन रात आगे बढ़कर नए मुकाम हासिल कर रहीं हैं। साक्षी मलिक, एम. सी. मैरी कॉम, दीपा कर्माकर, सानिया मिर्जा, हिमा दास, पीवी सिंधु, साइना नेहवाल, फॉगट सिस्टर्स, मिताली दोराई राज, हरमनप्रीत कौर, कोमालिका बारी, अपूर्वी चंदेला, मानसी जोशी, मनु भाकर, अनु रानी ने अपनी रूचि के क्षेत्र में कैरियर बनाया। महिला रेसलर पूजा ढांडा, एथलीट सपना बर्मन, राजीव गांधी खेल रत्न से सम्मानित पैरा एथलीट दीपा मालिक, दक्षिणी ध्रुव समेत कई पर्वत श्रंखलाओं को फतह करने वाली आईपीएस अधिकारी अपर्णा कुमार, अर्जुन पुरस्कार से सम्मानित पूनम यादव तथा माउंट एवरेस्ट पर चढ़ने वाली पहली भारतीय महिला अरुणिमा सिन्हा के जज्बे ने दिखा दिया कि महिलाएं कुछ भी कर सकती हैं। ऐसे में आवश्यकता केवल इतनी है कि उन्हें अवसर प्रदान किए जाएं।

- साहित्यिक योगदान: पिछले 6-7 दशकों से महिलाओं ने साहित्य सृजन में विशेष रुचि दिखाई है। लीला मजूमदार, रोमिला थापर, मृदुला सिन्हा, झुम्पा लाहिरी, अमृता प्रीतम, 
शोभा डे, अजीत कौर, एम. के. इन्दिरा, बर्नित बागची, महाध्थेता देवी जैसी शख्सियतों ने इस क्षेत्र में अभूतपूर्व सृजन कर न केवल साहित्य विस्तार किया साथ-ही-साथ अंतरराष्ट्रीय स्तर पर भारतीय महिला साहित्यकारों को एक नई पहचान दिलाई।

- सैन्य सेवा: भारतीय महिलाएं थल सेना, जल सेना, वायु सेना तीनों मोर्चों पर कमान संभाली नजर आने लगी है। सेना में स्थायी कमीशन देने के सुप्रीम कोर्ट के निर्णय ने इस पर मुहर भी लगा दी है। परेड एंडजुटेन्ट कैप्टन तानिया शेरगिल, भारतीय थल सेना अफसर प्रिया झिंगन, भारतीय सेना में बहादुरी पुरस्कार से सम्मानित मिताली मधुमिता, बहुराष्ट्रीय सैन्य अभ्यास करने वाली सोफिया कुरैशी, वायु सेना की पहली एयर मार्शल पद्मावती बंधोपाध्याय, फाइटर प्लेन उड़ाने वाली अवनी चतुर्वेदी, भावना कांत व मोहना सिंह ने विध्ध को भारतीय महिला सैन्य क्षमता का परिचय दिया।

- सामाजिक क्षेत्र: भारतीय महिलाओं में किसी भी चुनौती का प्रत्युत्तर देने की विलक्षण क्षमता है, जो अलग-अलग समय पर विभिन्न रूपों में प्रकट हो जाती है। यहां पुरुष वर्चस्व का पुरजोर विरोध के लिए हिंसात्मक साधन अपनाने वाली "गुलाबी गैंग" की महिलाएं भी मौजूद है, जो लाठी के जोर पर पुरुषों को सुधारने की क्षमता रखती हैं तथा तेजाब हमले जैसे जघन्य घटना के बाद भी स्वयं को संभालकर आत्मनिर्भर बनाकर, दूसरों को हर परिस्थिति का सामना डटकर करने की सीख देने वाली Sheroes की संस्थापक लक्ष्मी अग्रवाल जैसी सकारात्मकता रखने वाली लड़कियां भी मौजूद हैं। समाज सेवा का एक अन्य रूप हम केरल की पारंपरिक मार्शल आर्ट कलारीपयट्ट् को सिखाने वाली 79 वर्षीय मीनाक्षी अम्मा में भी देख सकते हैं,जो इसे आत्मरक्षा की कला मानकर लड़कियों को निशुल्क ही प्रदान कर देती हैं।

- संकटकाल में महिलाएं: इतिहास साक्षी है कि जब-जब देश पर कोई भी संकट आया, तब-तब देश की महिलाओं ने पुरुषों के कंधे से कंधा मिलाकर कार्य किया है। इस कोविड-19 काल में भी महिलाएं डॉक्टर से लेकर आशा कर्मचारी और ग्राम पंचायत के प्रधान के स्वरूप में इस महामारी से लड रहे हैं। ऐसी ही कुछ महिलाओं के उदाहरण हैं- वायरोलॉजिस्ट मीनल दखावे भोंसले, जिन्होंने भारत की पहली कोरोना टेस्टिंग किट बनाकर अपनी बेटी की डिलीवरी से ठीक 1 दिन पहले प्रशासन को प्रमाणन के लिए सौंपी। कैप्टन स्वाति रावल 22 मार्च को इटली में फंसे भारतीय छात्रों को बोइंग 777 स्वदेश लेकर आयीं। तेलंगाना की सबसे कम उम्र की सरपंच अखिला यादव कोरोना वायरस से गांव को बचाने के लिए गांव की प्रवेश सीमा पर बैठने लगीं हैं। तमिलनाडु के गांव में एक अस्पताल में काम करने वाली महिला एस. विनोथिनी. प्रेणनेंसी के 8 महीने में भी 250 किमी. का सफर तय कर हैल्थ सेंटर जातीं हैं।

भविष्य की उन्नत सम्भावनाएं: आधुनिक भारत की महिलाएं जीवन के प्रत्येक क्षेत्र में सर्वोत्कृष्ट प्रदर्शन कर रही हैं। पुरुष वर्चस्व के अनेक क्षेत्रों में महिलाओं ने अपनी जड़ों को जमा लिया है, जैसे कि चिकित्सा के क्षेत्र में डॉ आनंदीबाई जोशी, उड्डयन क्षेत्र में पायलट सरला ठकराल, वकालत के क्षेत्र में कोर्नेलिया सौराबजी ने स्वयं शुरुआत करके अनेक महिलाओं को प्रेरणा देकर इन क्षेत्रों में स्थापित किया।
परंतु यह ध्यान देने योग्य है कि अन्य क्षेत्रों में महिलाओं की संख्या अभी भी कम है, फिर भी उन क्षेत्रों में उनके भविष्य निर्माण की अनेक संभावनाएं हैं। समकालीन तौर पर वर्ष 2018 में देश की पहली महिला फायर फाइटर बनी तान्या सन्याल ने पुरुषों के लिए आरक्षित माने जाने वाले क्षेत्र में कदम रख कर अनेक महिलाओं की सोच को प्रभावित किया। इसी प्रकार रिक्शा चालन, टैक्सी चालन, कुरियर सेवा, पैराग्लाइडिंग जैसे क्षेत्रों में यद्यपि कुछ ही महिलाएं स्थापित हुई है तथापि उन्होंने अनेक महिलाओं के भविष्य संबंधी अवसरों को बढ़ा दिया है। इस कारण आशा की जाती है कि भविष्य में महिलाएं अन्य क्षेत्रों में भी आशातीत सफलता हासिल कर देश का नाम रोशन करेंगी।

निष्कर्ष:

राष्ट्र निर्माण की प्रक्रिया अत्यंत जटिल है, जिसमें देश के प्रत्येक नागरिक की सामाजिक, आर्थिक, राजनैतिक, चारित्रिक, नैतिक, शैक्षिक और सांस्कृतिक रूप से उन्नति की जाती है। देश में खाद्यान्न, विज्ञान, प्रौद्योगिकी, समाज कल्याण व सुख-सुविधाओं की प्रचुरता सुनिधित की जाती है। इस जटिल गतिशील प्रक्रिया में प्रत्येक नागरिक (महिला, पुरुष, बालक, वृद्ध सभी) का सहयोग में योगदान अनिवार्य है। देश की संपूर्ण जनसंख्या का आधा भाग महिलाओं से बना होता है। उनके द्वारा अन्य सभी की उत्पत्ति, विकास व कल्याण संभव हो पाता है। विगत कुछ वर्षों से महिलाओं की जीवन शैली में महत्वपूर्ण परिवर्तन आएं हैं, जिनसे उनके मूल्य, व्यवहार, संवेदना व जीवन दृष्टि स्पष्टतः प्रभावित हुई हैं। वे वर्तमान में जीवन के प्रत्येक क्षेत्र में पुरुषों से कंधे से कंधा मिलाकर चल रही हैं। सामाजिक परिवर्तन के चक्र के कारण ही भारतीय महिलाओं को अपनी पारम्परिक भूमिकाओं से आगे बढ़कर अनेक व्यापक उत्तरदायित्व संभालने की प्रेरणा मिली है। अब महिलाएं केवल गृहिणी की भूमिका तक ही सीमित नहीं हैं, अपितु जीवन के प्रत्येक पड़ाव पर आत्मनिर्भरता का परिचय देते हुए अपनी क्षमताओं, साहस व सृजनशीलता से उत्तम व आत्मनिर्भर राष्ट्र के निर्माण में अपना अभूतपूर्व योगदान देने लगी हैं।

\section{संदर्भ सूची}

1. https://yourstory.com/2016/06/women-socialreformers-india

2. https://m.dailyhunt.in/news/india/hindi/parichay+times +info-epaper-

paritime/rashtr+nirman+me+mahilao+ka+yogadan+bud dh+prakash-newsid-83213529

3. https://m-hindi.webdunia.com/womens-dayspecial/international-women-day-

118030500080_1.html?amp=1

4. http://mediapassion.co.in/?p=51339

5. https://www.punjabkesari.in/blogs/news/woman-is-janani-1134312

6. https://hindi.thequint.com/voices/opinion/india-womenin-coronavirus-battle-covid19

7. https://www.amarujala.com/photogallery/columns/blog/coronavirus-covid-19-lockdowneffect-on-women-role-of-females-in-fighting-withdisasters

8. https://feminisminindia.com/2019/12/24/13-indiansportswomen-2019/

9. https://indianexpress.com/article/lifestyle/art-andculture/international-rural-womens-day-heres-howindian-women-are-keeping-dying-crafts-alive-4891315/ 